\title{
Debunking the Myth of Pregnancy Doping
}

\author{
Elizabeth A. Sorensen, Ph.D., RN, CNOR \\ Wright State University
}

\begin{abstract}
The notion that pregnancy and abortion are forms of doping has persisted for 20 years. Popular and scientific literature on pregnancy/abortion doping was critically analyzed to compare pregnancy/abortion doping with definitions of doping and blood doping and to compare pregnancy/abortion doping themes to current scientific knowledge. Main themes included oxygenation advantage and hormonal advantage. During pregnancy, maximal oxygen uptake may improve but not exercise performance. Human chorionic gonadotropin, the only pregnancy hormone on National Collegiate Athletic Association and United States Anti-Doping Agency banned substances lists, increases during pregnancy but there is no evidence that hCG enhances athletic performance in women. Recommendations include revising USADA and NNCAA policies into congruence with World Anti-Doping Agency policies which ban hCG for men only.
\end{abstract}

During the past seven years of advocating for college student-athlete athletic department pregnancy and parenting policies, popular nonscientific literature (websites, blogs, and personal anecdotes) and scientific literature have been examined to detect barriers to student-athlete health and policy change. One barrier is a persistent belief in popular literature that athletes can use pregnancy and/or abortion to enhance competitive performance; i.e., as a form of prohibited blood doping. The scientific and nonscientific resources on pregnancy and abortion doping have considerably diverged over the past 20 years. The purposes of this paper were to examine the biophysical themes in popular and scientific definitions of doping, blood doping, and pregnancy/abortion doping, compare pregnancy/abortion doping to current scientific knowledge, and make recommendations to the stakeholders: student-athletes, coaches, athletic trainers, team physicians, athletic and university administrators, university faculty, the United States Anti-Doping Agency (USADA) and the National Collegiate Athletic Association (NCAA).

The fact that doping has occurred since the beginning of athletic competition (e.g., Houlihan, 1999; Public Television transcript, 2008) is not being questioned. Excellent analyses of the history of doping (e.g., Franke \& Berendonk, 1997;

The author is an Assistant Professor of Nursing and Faculty Athletic Representative, College of Nursing and Health, Wright State University, Dayton, Ohio. 
O'Reilly \& Madill, 2007; Pablinger \& Gruber, 2005) and sociopolitical influences on doping (e.g., Houlihan, 1999) are available elsewhere. Numerous scientific publications have been written on the medical procedures and pharmacological agents used in doping, the harmful effects of doping, and the tests used to detect doping (e.g., Catlin, Fitch \& Ljundqvist, 2008). These important scientific resources serve to inform policy makers who enact policies strive to "level the playing field" for athletes who compete on the local, national, and international levels. Optimally, all stakeholders use the best available scientific evidence to guide their responses to conditions which affect the well-being of athletes and sports. Unfortunately the stakeholders' ability to access and use scientific evidence is not always optimal.

First, scientific statements may be misconstrued or misunderstood. In rare instances scientists' statements may have unintended consequences when lay individuals use them as the basis for inaccurate statements about emotionally-laden topics like pregnancy, abortion, athletic participation and doping. Multiple popular literature sources (e.g., Hamilton, 2006; Maxwell, 2002; Mikkelson, 2002; Passignano \& Crutcher, 2002; Religious Tolerance, 2002; Webb, 2004; Wolff and O'Brien, 1994) cited scientists' statements in support of their reports that pregnancy and abortion can be used by athletes as a form of illegal blood doping for competitive advantage. Given the frequency of scientific citations, critical review was warranted.

Second, some stakeholders who are seeking information-like pregnant athletes and their partners, parents, coaches, and athletic administrators-may find the numerous resources in popular literature more readily accessible and more comprehensible than scientific literature which contains academic and medical terminology. When scientific literature is uncovered in response to an internet search, the literature may only available proprietarily, i.e., for a fee, while popular sites are free of cost. The stakeholder may lack sufficient education and critiquing skills to effectively assess the scientific credibility of the information source. Thus, reviewing both popular and scientific literature on the topic of pregnancy and abortion doping was important to determine lay information and examine congruence with scientific literature.

Clearly, pregnancy occurs in the athlete and student-athlete population. Pregnancy (their own or their partner's) occurs to an estimated 10-15\% of college student-athletes per year (Hogshead-Makar \& Sorensen, 2008). Arguably most are unintended, precipitating a crisis resulting in destabilized coping (Sorensen, Sincoff \& Siebeneck, 2009). Considerable anecdotal evidence exists that some studentathletes respond to the event of pregnancy in unhealthy, unsafe ways: concealing pregnancy while continuing to train and compete (Ford, 2004; Lehman College, 2001; Potts, 2001; Schonbrun, 2007; Willis, 2001), feeling forced to abort (Anonymous, 1998; Portnoy, 2004; Rovegno, 2007), feeling forced to choose between their financial aid and pregnancy (Rovegno, 2007), and fearing expulsion or other negative stereotyping (Anonymous, 1998). Two freshmen student-athletes were arrested for the homicides of their term infants (Plushnick-Masti, 2007; Zander 2007). One student-athlete's computer memory contained evidence of internet searches for pregnancy termination and inducing fetal death (Associated Press, 2007), supporting the notion that popular literature is a source of information for the student-athlete stakeholder. The extent to which the student-athletes mentioned above sought out nonscientific information and whether any acted out of fear of being accused of pregnancy doping was unclear. While no scientific studies have 
established student-athletes' information seeking processes, clearly their decisions and actions were not guided by accurate scientific information, legal advice, or effective policies.

Yet, national attention to the mistreatment of pregnant student-athletes (e.g., Monroe, 2007; Rovegno, 2007) recently motivated the NCAA to advocate for student-athlete health by protecting athletic financial aid in the event of pregnancy (NCAA, 2008a) and by distributing a comprehensive set of policy guidelines (Hogshead-Makar \& Sorensen, 2008) to its member institutions. The latter document referenced a "short-lived myth that pregnancy enhanced [athletic] performance" (Hogshead-Makar \& Sorensen, 2008, footnote 1, p. 106). This essay provides evidence of the scope of the problem and the "false hypothesis that physiologic changes of pregnancy mimic blood doping" (ibid.).

Debunking the myth of pregnancy doping has the potential to positively influence athletes' health and inform policy through providing accurate scientific information. Accurate information may potentially increase the likelihood that pregnant athletes will seek help rather than conceal their pregnancies. The research question guiding this study was, "to what extent are pregnancy and/or abortion forms of doping or blood doping?".

\section{Method}

The topic of pregnancy and abortion doping was initially identified in 2004 as a potential barrier to healthy student-athlete pregnancy, specifically as a potential negative stereotype of pregnant athletes, within a larger search for health and policy variables affecting intercollegiate student-athlete pregnancy and parenting. Since the phenomenon seemed scientifically unlikely, an initial internet search was conducted in 2006 using the key words "athlete", "doping" and "pregnancy doping" to determine the frequency of nonscientific resources (websites, blogs, media reports and anecdotal stories) and examine their content. The first search revealed a surprising number of personal descriptions, citations and attributions of statements to individuals identified as scientists, so a second internet search was conducted.

The second internet search used the keywords "abortion doping", "athlete", "blood doping", "college student athlete", "doping”, "doping policy", "exercise", "pregnant", "pregnancy", "pregnancy doping" and the names of specific scientists mentioned. The second search was conducted for the purpose of establishing a chronological timeline for the proliferation of the phenomenon, examining the credentials of scientists cited, examining scientific citations, and examining regulatory statements and other policy guidelines. Concurrently, a search of academic literature was conducted to identify research studies which could establish physiological factors which might support or refute pregnancy as a performance enhancing condition. The search for scientific literature was conducted through a university multiple database search engine using the same keywords: "abortion doping", "athlete", "blood doping", "college student athlete", "doping", "doping policy", "exercise", "pregnant", "pregnancy", "pregnancy doping" and the names of specific scientists mentioned. Further searches targeted "human chorionic gonadotropin", "hCG", and "testosterone". Literature from maternal-child nursing, obstetrical medicine, sports medicine, and sports regulatory bodies were examined. The internet and 
academic search strategies were repeated four times per year through 2009 to detect new resources.

The strength of each data source was assessed using a seven-level evidence hierarchy (Polit \& Beck, 2008). Systematic reviews of randomized controlled clinical trials were considered the highest level of evidence (Level I). Level II evidence consisted of single randomized followed by nonrandomized controlled clinical trials. Subsequent levels included systematic reviews of correlational studies (Level III) and single correlational studies (Level IV). Systematic reviews of descriptive and physiologic studies (Level V) and single descriptive and physiologic studies (Level VI) were followed by the lowest level of evidence consisting of the nonpublished opinions of experts and authorities (Level VII; Polit \& Beck, 2008, p. 31). Internet resources were considered scientifically least credible yet were important in establishing the frequency and chronology of the phenomenon and assessing lay beliefs.

All academic resources were examined to distinguish primary from secondary research sources (Polit \& Beck, 2008) and retained for critique. Primary sources within the past 10 years were considered optimal. Internet resources including websites, blogs, media accounts, and personal anecdotes were retained for analysis if an author and date could be clearly ascertained. Care was taken to retain an open scientific perspective about the potential for truth in the phenomenon, in other words, to accept the descriptions in scientific and popular literature without immediate prejudice or judgment as to their merit. The literature sources on pregnancy/abortion doping were analyzed to extract evidence of purported performance enhancement and competitive advantage, and to extract themes.

\section{Results}

\section{Defining Doping, Blood Doping and Pregnancy/Abortion Doping}

Doping. The United States Anti-Doping Agency (USADA; 2006) and World Anti-Doping Agency (WADA; 2009a) defined doping as the presence of a prohibited substance or its metabolites or markers; refusing of or unavailability for sample collection; use or attempted use, possession, trafficking, administration or attempted administration of prohibited substances or methods; or tampering or attempting to tamper with doping control. The National Collegiate Athletic Association (NCAA; 2008b) extended the definition of doping to include substances or procedures which artificially induce physiologic advantage or harm, and provided a lengthy list of banned drug classes and substances. The NCAA Bylaws direct that random, objective, unannounced testing for the presence of banned substances should take place regularly in college athletic departments, and that purposive objective testing for banned substances is conducted at championship events (NCAA, 2008c). A substance or method is banned if it enhances performance and/or poses a threat to an athlete's health (WADA, 2009a). The USADA and WADA hold both athletes and their support persons liable for violations which include "assisting, encouraging, aiding abetting, and covering up or complicity" in an antidoping rule violation (USADA, 2006; p. 3) and for consequences of rule violations (WADA, 2009a). 
Blood Doping. Blood doping is defined as methods or procedures which physiologically enhance the delivery of oxygen to an athlete's muscles, artificially increasing stamina and performance, including increasing red cell mass to improve performance (Sawka, Joyner, Miles, Robertson, Spriet \& Young, 1996) and administration of blood, red blood cells and/or related products to an athlete (USADA, 2006). Blood doping may be accomplished by withdrawing blood from an athlete at some time before competition, continued athletic training in a depleted [anemic] state, then readministration of the athlete's blood before competition to enhance red cell mass and thus oxygen-carrying capacity (USADA, 2006). The NCAA (2008b) defines blood doping as the intravenous injection of whole blood, packed red blood cells or blood substitutes, and any evidence confirming use. The WADA defines blood doping as misuse of techniques and/or substances to increase red blood cell mass, which allows the body to transport more oxygen to muscles and increase stamina and performance. Specific techniques include the use of blood transfusions, and the administration of oxygen carriers and substances which stimulate the body to produce more red blood cells, e.g., erythropoietin (WADA, 2009b). McGovern, a journalist, defined blood doping as a "well-known scheme in which athletes take drugs that enhance their blood supply and oxygen supply [for] up to a $10 \%$ boost in athletic performance" (2002).

Pregnancy/Abortion Doping. The intent in this section was not to deny the existence of past events or critique specific individuals' beliefs about pregnancy or abortion. The intent of this section was to chronicle the progression of reports about pregnancy/abortion doping in popular and scientific literature, extract themes and scientific arguments used in the reports, and lay a basis for comparison with current scientific evidence. For the purposes of this paper, the definition of pregnancy/abortion doping was derived from established elements (italicized below) of doping and blood doping. Pregnancy/abortion doping are herein defined as the misuse of pregnancy and/or abortion by a female athlete, her coach or support person to artificially induce physiologic advantage, increase red blood cell mass, enhance the delivery of oxygen and boost athletic performance. Pregnancy/ abortion doping would be detected objectively by the presence of a substance (or its metabolites or markers) which is listed on the regulatory organization's list of banned drug classes or substances. The definition of pregnancy/abortion doping and consequences for this form of doping would extend to anyone who assists, encourages, aids, abets, or covers up pregnancy and/or abortion.

\section{Pregnancy/Abortion Doping}

Timeline 1988-2008. The earliest statement on pregnancy doping was attributed to Dr. Risto Erkkola, a Finnish physician who in 1988 reportedly stated, "now that drug testing has become routine, pregnancy has become the favourite [sic] way of getting an edge on competitors" (quoted in Hamilton, 2006; Maxwell, 2002; Mikkelson, 2002; Passignano \& Crutcher, 2002; Religious Tolerance, 2002; Webb, 2004). Wolff and O'Brien (1994) described in Sports Illustrated the story of Olga Karasyova, a 1968 USSR gold medalist in gymnastics, whose coaches ordered her to get pregnant then abort at 10 weeks of pregnancy, because pregnancy was believed to produce more male hormones which would give her greater strength 
and stamina. Another frequently cited source on pregnancy and abortion doping was Dr. Paul-Erik Paulev, a Danish professor of physiology at the University of Copenhagen. Dr. Paulev wrote these 64 words in an 8,040-word Respiratory System chapter within his on-line Textbook in Physiology and Pathophysiology (1999b):

Pregnancy seems to increase muscle strength in female athletes. Female top athletes - just following the period where they gave birth to their first childhave set world records. Of course, this is acceptable as a natural and unintended event. However, in some countries female athletes have become pregnant for 2-3 months, in order to improve their performance just following an abortion.

Dr. Paulev's statements were not referenced to any scientific studies, and repeated attempts to contact him personally have been unsuccessful. It is possible that Drs. Erkkola and Paulev never intended for their statements to have such great impact.

Passignano and Crutcher (2002) cited Dr. Erkkola as support for the statements that "getting pregnant to abort as a way to improve athletic performance is not new. [Pregnancy] increases the volume of oxygen and nutrients in doped blood. Pregnancy dopes your blood". The Life Issues Institute (2002) cited Erkkola, Paulev, and Passignano and Crutcher as support for the statements, "recovering from abortion takes a few days, then [the athlete is] left with the enhanced muscle mass and blood capacity that was meant to carry her through her pregnancy". The American Life League's Pro-Life Activist's Encyclopedia (undated) defines pregnancy/abortion doping as "[a practice in which] early pregnancy would enhance athletic performance. Women are artificially inseminated by coaches, compete in events from 5-7 weeks of pregnancy then travel en masse to local abortion mills to kill their unborn children".

McGovern (2002), a journalist, cited Passignano and Crutcher as support for the statements, "early pregnancy boosts a woman's blood volume tremendously. Getting pregnant 2-3 months before an event and having an abortion days prior [gives] as much as $10 \%$ enhancement". Operation Rescue West (2002a) published a news release stating:

Female Olympians routinely get pregnant 2-3 months prior to competition to get an edge over the competition. The pregnancy changes a woman's physiology causing a strengthening of the muscle tissue and an extra 'boost' of oxygen to the athlete's blood. Then just two weeks before competition, the baby is killed by abortion but the physical benefits linger, increasing the athlete's ability to perform. This process is known as 'blood doping'. Women around the globe repeat this cycle of pregnancy and abortion in order to further their careers. Olympic 'heroines' are routinely built on the bloody foundation of the aborted bodies of their own pre-born sons and daughters.

Mikkelson (2002) posed the question, "can female athletes supercharge through aborting a fetus just before competition, reabsorbing additional hormones? [This practice is] akin to blood doping but in this case it's hormone levels not red blood cells". Mikkelson reported "delegates' statements" during the 1988 First Permanent World Conference on Anti-Doping in Sport that "some Eastern European female athletes were having themselves artificially inseminated then aborting the fetuses 2-3 months later to take advantage of a perceived hormone boost". Webb (2004) 
described abortion doping as "getting pregnant to boost athletic performance. Abortion doping enhances the body just like steroids do-by increasing testosterone level", citing Erkkola as support. Abrahamson (2006) wrote that a pregnant Russian skier "won three medals at the Salt Lake City Olympic Games in 2002", adding, "medical experts have long known that pregnancy can lead to a measureable improvement in an athletic performance-because pregnancy produces an abundance of oxygen-carrying red blood cells, boosting endurance. ...the 'effects of pregnancy parallel blood doping' but athletes 'cease to gain performance benefits after 14 to 15 weeks of gestation". Hamilton (2006) while discussing elective performance enhancement surgeries reported that surgical abortion was "used for the purpose of enhancing athletic performance", and that "pregnancy days prior to an event can actually provide as much as a $10 \%$ enhancement" (p. 42). Hamilton further observed that "the International Olympic Committee has banned it as a form of doping" and implied that "other governing organizations ... seem to be condoning this surgical procedure by their silence" (2006, p. 42). Stanek (2007) stated, "It's a well known fact that female endurance athletes do tend to perform better after childbirth". A Bulgarian tennis athlete tried to explain a high level of nandrolone in her blood sample by saying she was pregnant and then miscarried (Irish Times, 2007). Epstein (2008) reported in a Sports Illustrated article that,

Doctors now speculate that pregnancy may be a performance enhancer. There is evidence that pregnancy can help an athlete. One change in a pregnant woman's body is increased blood volume (because two people are being supplied). Once the baby is born, the extra red blood cells that remain in the mother's system carry extra oxygen to the muscles, an effect akin to doping with EPO.

In summary, the phenomenon of pregnancy/abortion doping has been reported in the popular literature over the past 20 years and as recently as 2008 . Both early and recent descriptions of the phenomenon have referred to "scientists", "doctors" or "medical" statements as support for the credibility of the statement. These citations warrant critical examination.

\section{Major Themes}

Two main biophysical themes were extracted from content analysis of the literature on pregnancy/abortion doping: an oxygenation advantage and a hormonal advantage. Each theme is discussed below. Current scientific evidence will be used to examine each theme's scientific merit.

\section{Oxygenation Advantage}

Pregnancy and/or abortion have been described in popular literature as resulting in a competitive advantage related to oxygenation. The oxygenation advantage was reported to enhance athletic performance as much as 10\% (Passignano \& Crutcher, 2002). Pregnancy-doped blood was reported to contain an increased volume of oxygen and nutrients (Life Issues Institute, 2002; McGovern, 2002; Passignano $\&$ Crutcher, 2002). Early pregnancy was described as a time of increased blood volume, cardiac output and oxygen availability (McGovern, 2002). 
Current scientific evidence on pregnancy and specifically early pregnancy supports an increase in total blood volume and suggests improved maximal oxygen uptake but does not support a conclusion of athletic performance enhancement. Frye (1997) explains:

The amount of blood in a pregnant woman's circulation increases as pregnancy advances, with peak volume occurring at 28 to 30 weeks [of a 40 week term pregnancy]. Blood volume increases from about 3.5 to 5.6 quarts for a woman whose pre-pregnant weight was 130 pounds. This occurs because the mother's body must provide support for the enlarging placenta: supporting placental growth, fetal growth, and protecting against [cardiovascular] shock during birth. Blood volume expansion is primarily plasma, which begins to increase at about 8 weeks of pregnancy at plateaus at 28-30 weeks of pregnancy. Red blood cell volume begins to rise at 18 weeks of pregnancy and continues to rise until term [38-40 weeks]. Plasma volume expands 50-60\% and the red blood cells, which increase by only $30 \%$, are correspondingly diluted. This is the mechanism of the physiologic "anemia" of pregnancy. It is therefore normal for hemoglobin [concentration] to drop about two grams [per deciliter] by 28 weeks (p. 889).

Thus, if in response to McGovern's 2002 statement, we define "early pregnancy" as before 18 weeks of pregnancy, the increase in total blood volume during this time is related to plasma expansion. Plasma does not improve oxygenation. When the oxygen-carrying red cell volume begins to rise (about 18 weeks), its total increase is outpaced by total plasma volume increase. The $30 \%$ expansion in red blood cell volume listed above may be optimistic. Gordon (2002) reported that in the absence of iron supplementation, red blood cell volume increased only $18 \%$.

Hemoglobin concentration, the oxygen-carrying component of red blood cells, normally ranges from 12 to $16 \mathrm{~g}$ per deciliter $(\mathrm{g} / \mathrm{dl})$ for adult women (Gaedeke, 1995 , p. 375) but drops to $10 \mathrm{~g} / \mathrm{dl}$ by 28 weeks of pregnancy due to hemodilution. After 28 weeks of pregnancy, hemoglobin levels of $10 \mathrm{~g} / \mathrm{dl}$ are the lower limit of normal (Frye, 1997). Hemoglobin levels between 10 and $14 \mathrm{~g} / \mathrm{dl}$ result in feelings of cardiovascular palpitation, shortness of breath on exertion and fatigue (Gaedeke, 1997). In a study of exercising pregnant individuals $(n=10$, mean age $30 \pm 3$ years) hemoglobin levels at 25 weeks of pregnancy averaged $10.8 \pm 0.3 \mathrm{~g} / \mathrm{dl}$ before exercise and $12.5 \pm 0.5 \mathrm{~g} / \mathrm{dl}$ after exercise. At 35 weeks of pregnancy participants' hemoglobin levels averaged $10.8 \pm 0.3 \mathrm{~g} / \mathrm{dl}$ before exercise and $13.0 \pm 0.4 \mathrm{~g} / \mathrm{dl}$ after exercise (McMurray, Hackney, Katz, Gall \& Watson, 1991). Hemoglobin levels higher than $12 \mathrm{~g} / \mathrm{dl}$ may indicate hemoconcentration; as "pregnancy results in a greater-than-normal exercise induced hemoconcentration" (McMurray, et al., 1991, p. 1454).

An early study of maximal oxygen uptake $\left(\mathrm{VO}_{2 \max }\right)$ suggested that pregnancy might enhance oxygenation. Clapp and Capeless (1991) studied exercise intensity and $\mathrm{VO}_{2 \max }$ in a convenience sample of healthy, well-conditioned, nonpregnant recreational athletes ( $n=40$; age range $26-36$ years) using a prospective, longitudinal, between-subjects design. Twenty participants became pregnant during the study; for these individuals measures were taken prepregnancy and at 6-8 weeks, 12-20 weeks, and 36-44 weeks postpartum. Twenty participants remained nonpregnant; 
measures were taken at the beginning and end of a 15-18 month period. Fitness (via morning pulse rate and $\mathrm{VO}_{2 \max }$ ), exercise performance (via heart rate and number of minutes exercising daily), and exercise intensity (the product of exercise minutes and $\mathrm{VO}_{2 \max }$ ) were assessed. The two groups were equivalent on all variables before pregnancy. Although the authors found that $\mathrm{VO}_{2 \max }$ in the postpartum group was significantly higher than in the nonpregnant group, exercise performance significantly declined at all time points for the pregnant individuals. Neither exercise time nor performance returned to prepregnancy levels for the pregnant group. This study could have been strengthened by reporting laboratory results, e.g., hemoglobin levels, and participants' perceived exertion, shortness of breath, and fatigue. It is possible that the expectations or motivations of pregnant participants to excel during the study introduced a Hawthorne effect (Polit \& Beck, 2007, p. 264). Participants who did not become pregnant would not have had similar motivations.

In contrast Lotgering, Van Doorn, Struijk, Pool and Wallenburg (1991) studied maximal heart rate, oxygen uptake $\left(\mathrm{VO}_{2}\right)$ and ventilation in a group of 33 pregnant individuals (mean age $30.9 \pm 0.7$ years). Each participant's 7-week postpartum performance used as a nonpregnancy comparison value for their bicycle and treadmill performances at 16, 25 and 35 weeks of pregnancy. The authors found a consistent but nonsignificant decrease in exercise performance over the course of pregnancy compared with the postpartum measurement, and no relationship between pregnancy status and maximal oxygen uptake $\left(\mathrm{VO}_{2}\right)$. Bessinger, McMurray and Hackney (2002) measured maximal $\mathrm{VO}_{2}$ at 22 and 33 weeks of pregnancy and 14 weeks postpartum in a sample of 12 regularly-exercising pregnant individuals (mean age $32 \pm 4$ years). The authors found that $\mathrm{VO}_{2}$ at 22 weeks was significantly lower than at 33 weeks of pregnancy when at rest but not during exercise. No differences related to pregnancy status were found.

In summary, a student-athlete's oxygenation during early pregnancy can be expected to reasonably parallel the scientific descriptions of normal pregnancy. Total blood volume before 18 weeks of pregnancy will increase, but the increase will consist primarily of plasma rather than oxygen-carrying red blood cells. Beginning at 18 weeks, red blood cell increase may range from 18 to 30\% (Gordon, 2002), depending on iron intake. Athletes should experience the normal physiological anemia of pregnancy. Hemoglobin concentration should range around $10 \mathrm{~g} / \mathrm{dl}$., with resultant normal feelings of fatigue and shortness of breath. Regardless of oxygenation changes, none of the studies supported a conclusion of athletic performance enhancement. If, for the sake of counterargument, pregnancy and/or abortion were forms of blood doping (defined as techniques and substances that result in elevated red blood cells; NCAA, 2008b; USADA, 2008; WADA, 2008) then maternal hematocrit, hemoglobin levels, and exercise tolerance would all be expected to increase in "early pregnancy" (e.g., McGovern, 2002) rather than decrease. Therefore the Oxygenation Advantage proposition fails the test of boosting athletic performance.

\section{Hormonal Advantage}

The second prevalent theme described a hormonal advantage during pregnancy which could enhance athletic performance. Several authors have proposed an association between pregnancy and increased muscle mass, strength, or stamina (Hamilton, 2006; Life Issues Institute, 2002; Mikkelson, 2002; Operation Rescue 
West, 2002b; Wolff \& O'Brien, 1994) possibly as a result of producing more male hormones (Wolff \& O'Brien, 1994). The increased muscle mass was purported to persist postabortion (Life Issues Institute, 2002; Operation Rescue West, 2002b). In one story, an athlete attempted to explain the presence of the steroid hormone nandrolone by saying she had recently miscarried her pregnancy (Irish Times, 2007).

Current scientific evidence does not support a conclusion of hormonal advantage resulting in performance enhancement. A comprehensive description of the complex endocrine mechanisms necessary to initiate and sustain pregnancy is beyond the scope of this paper and available elsewhere (e.g., Davidson, London \& Ladewig, 2008; Frye, 1997). The literature analysis for this paper was focused on cross-referencing normal hormones of pregnancy with current authoritative lists of banned hormones and substances, then examining the resulting hormones for their potential performance-enhancing effects. The hormones of normal pregnancy include human chorionic gonadotropin (hCG), human placental lactogen (hPL), estrogen, progesterone, and relaxin (Davidson et al., 2008; Frye, 1997). Of these, the World Anti-Doping Agency (2009b) bans hCG and its analog leutenizing hormone (LH) for men only. LH is similar in function to hCG (Davidson et al., 2008). The USADA (2006) and NCAA (2008) ban hCG for athletes of both genders. The scientific bases for these policy differences regarding hCG warrant examination.

Human chorionic gonadotropin (hCG). Human chorionic gonadotropin is produced by the anterior pituitary of normal adult men and adult nonpregnant women, where normal levels range from 0 to 5 milliunits per milliliter $(\mathrm{mIU} / \mathrm{ml}$; Frye, 1997, p. 112). In men, hCG acts upon the testes to stimulate testosterone production (Kicman, Brooks \& Cowan, 1991). The normal total and free testosterone levels in men range from 280 to 1100 nanomoles per liter $(\mathrm{nm} / \mathrm{l}$, Frye, 1997). In a double-blind, randomized clinical study of healthy men with normal testosterone levels ( $n=61$, age range $18-35$ years), increased muscle mass, strength, and endurance was directly dependent upon testosterone dose (Bhasin, Woodhouse, Casaburi, Singh, Bhasin, Berman et al., 2001). In other words hCG is clearly performance enhancing in men. Handelsman (2006) explains:

In normal men, hCG produces a sustained and dose-dependent increase in blood testosterone concentrations through stimulation of Leydig cell testosterone secretion. Typically, the basal blood concentrations ( $20 \mathrm{nmol} / \mathrm{liter})$ are increased to concentrations of 30-40 nmol/1, peaking between two and four days after a single injection. These markedly increased blood testosterone concentrations, within $10-30 \mathrm{nmol} / 1$, are with the range defined experimentally as having a log-linear relationship with increased muscle mass and strength in men. Hence [the doping] prohibition of hCG for men is well justified (p. 1649).

Human chorionic gonadotropin in women. Clearly, hCG produces a clear dose-dependent rise in testosterone which enhances performance in men, but does a similar relationship occur in women? In nonpregnant normal adult women, total blood testosterone levels ranges from 0.52 to $2.43 \mathrm{nmol} / \mathrm{l}$ (Frye, 1997, p. 357). Filicori, Cognigni, Gamberini, Parmegiani, Troilo and Roset (2005) administered a daily dose of $200 \mathrm{IU}$ of hCG to nonpregnant women ( $n=48$, age range 29-39 years). Carmina, Wong, Chang, Paulson, Sauer, Stanczyk and Lobo (1997) administered 10, 000 IU of hCG to a group of women with normal ovarian 
function ( $n=15$, mean age $28 \pm 1$ years). In both of these studies, the elevation in participants' blood testosterone level averaged 1.1 nanograms per milliliter (ng/ ml; Carmina et al., 1997; Filicori, et al., 2005), i.e., "about half of the daily normal diurnal rhythm in blood testosterone concentration" in women, which is "unlikely to have any measurable effect on muscle mass or strength" (Handelsman, 2006, p. 1650). Human chorionic gonadotropin has negligible, if any, stimulation of blood testosterone concentrations in nonpregnant women (Handelsman, 2006, p. 1649; Kicman, et al., 1991, p. 78; Stenman, Hotakainen \& Alfthan, 2008; p. 569). In nonpregnant women, hCG stimulates the ovary to produce progesterone and estradiol, not testosterone (Stenman, Hotakainen \& Alfthan, 2008). Thus, there is no scientific evidence that hCG is performance-enhancing in nonpregnant women.

In pregnant normal adult women, the fertilized, implanted ovum and then the placenta produce increasingly elevated levels of hCG, which peaks at 7-10 weeks of pregnancy between 25,700-288,000 $\mathrm{mIU} / \mathrm{ml}$ then gradually declines (Frye, 1997; Kicman, Brooks \& Cowan, 1991). In the second and third trimesters of pregnancy, hCG ranges from 4060 to $65,400 \mathrm{mIU} / \mathrm{ml}$ and $3640-117,000 \mathrm{mIU} / \mathrm{ml}$ respectively (Frye, 1997, p. 112). After several days postpartum, hCG returns to prepregnant levels. In pregnant women hCG stimulates the production of estrogens and progesterone (Davidson et al. 2008; Stenman, Hotakainen \& Alfthan, 2008), which do not have ergogenic effects. In pregnancy, estrogens cause enlargement of the uterus and breasts, and increase uterine \& fallopian contractility; progesterone decreases uterine contractility and sustains the pregnancy (Davidson et al., 2008).

Summary. The gender-specific scientific evidence on the ergogenic effects of hCG, i.e., performance enhancement has been demonstrated in men and not in women, may be the reason that the World Anti-Doping Agency currently bans the presence of hCG for male athletes only and not for female athletes. The WADA may also decline to ban hCG testing for women for ethical reasons. Routine urine testing for hCG in female athletes is "considered an invasion of female athlete privacy" (Handelsman, 2006, p. 1649) for three reasons: 1.) a lack of scientific evidence for hCG-related performance enhancement, 2.) high levels of hCG are experienced by normal pregnant women without negative health outcomes, and 3.) routine testing for hCG can reveal the presence of unexpected pregnancy or miscarriage with devastating psychological consequences to the athlete (Handelsman, 2006). If, for the sake of counterargument, hCG was performanceenhancing for women, i.e., pregnancy and its resultant high levels of hCG were a form of doping, then all pregnant women would be logically expected to develop extraordinary musculature, strength and endurance. Thus, since there is no scientific evidence that establishes that hCG has ergogenic effects in women, then the Hormonal Advantage proposition fails the test of physiological advantage to boost athletic performance.

\section{Minor Themes}

Two minor themes were also found during analysis of the literature. The first minor theme was a suggestion that there is an optimal timing of pregnancy or abortion in order for competitive advantage. The time frames ranged from 5 to 7 weeks (American Life League undated), 10 weeks (Wolff \& O’Brien, 1994), and 2-3 
months of pregnancy (Life Issues Institute, 2002; McGovern, 2002; Paulev, 1999). The optimal timing of abortion in order for competitive advantage has been reported as precompetition (Wolff \& O'Brien, 1994), just before competition (Paulev, 1999); days or a few days before competition (Life Issues Institute, 2002; McGovern, 2002; Passignano \& Crutcher, 2002) and just after a competition (American Life League). The reasons for these varied time frames have no clear basis in science, given that pregnancy does not result in performance enhancement.

Moral and ethical failures were the second theme, although failure on whose part was inconsistent. Pregnancy/abortion doping was described in popular literature as immoral (American Life League) and carried out illicitly (Abrahamson, 2006). Responsibility for pregnancy doping was ascribed to coaches and athletic trainers (American Life League). A coach or athletic trainer unethically used power over the athlete to artificially inseminate her (American Life League), to order the athlete to get pregnant (Wolff \& O'Brien, 1994), and to order termination of the pregnancy (American Life League; Wolff \& O'Brien, 1994). Some authors suggested that pregnancy/abortion doping continues as an athletic practice because it is less detectable than other drug tests and impossible to enforce, stop or ban (Lifesite, 2002; McGovern, 2002). In some cases pregnancy doping was described as the intended goal of an athlete's pregnancy (American Life League; Life Issues Institute, 2002; McGovern, 2002; Wolff \& O’Brien, 1994) while others described doping as a natural, unintended consequence of pregnancy (Passignano \& Crutcher, 2002; Paulev, 1999). If pregnancy doping was described as the intended goal of pregnancy, the decisions to become pregnant and to terminate pregnancy were ascribed to coaches (American Life League, undated; Wolff \& O'Brien, 1994) or to the athlete herself (Life Issues Institute, 2002; Passignano \& Crutcher, 2002; RealChoice, 2007). Authors that described pregnancy doping as the intended goal used more negative words, e.g., horrible, immoral, scheming (McGovern, 2002), gruesome (Lifesite, 2002), and abhorrent (Abrahamson, 2006) than those who implied that pregnancy doping was an unintended consequence of pregnancy (Passignano \& Crutcher, 2002; Paulev, 1999).

\section{Discussion}

The persistence of the notion that pregnancy and/or abortion can be used by female athletes to improve athletic performance is a barrier to healthy student-athlete pregnancy and to the health of sports. The myth seems to have originated within early scientific statements (e.g., Erkkola, Paulev) which have now been eclipsed by current science. Popular literature as recently as 2008 continues to perpetuate the myth and inaccurately portray pregnancy and abortion. A little information can sometimes be a dangerous thing.

Although the myth of pregnancy doping has been scientifically debunked, the persistent negative characterizations of pregnancy in athletes are of concern for two reasons. The first reason is that negative, judgmental character assumptions may discourage pregnant athletes from seeking the help they need. Hogshead-Makar and Sorensen (2008) argued that an intercollegiate student-athlete's pregnancy is rarely intended. The challenges of unintended pregnancy can cause psychological disequilibrium; if unresolved, maladaptive behaviors may result (Messer, Dole, 
Kaufman \& Savitz, 2005). In two separate instances during 2007, freshman intercollegiate student-athletes became pregnant, concealed their pregnancies, delivered in their dorm rooms, and killed their newborn infants (Plushnick-Masti, 2007; Zander, 2007). While these two individual athletes' states of mind cannot be assumed, it is possible that the outcomes of their pregnancies were affected by fears of negative stereotyping, difficulties coping or an unsupportive policy environment. The second reason for concern is that these negative characterizations focus exclusively on female athletes. Male athletes are potentially equal partners in pregnancy and do become parents while in college. The focus on female athletes disregards the potentially real concerns of male athletes who may have concerns about their partner's health during pregnancy and their ethical, financial, and legal responsibilities regarding their partner's pregnancy (Sorensen, Sincoff \& Siebeneck, 2009). Moving as a nation toward a more appropriate, gender-equitable, ethical response to athlete pregnancy must begin with disseminating accurate scientific knowledge. Changing the negative stereotypes and existing institutional cultures may take much longer.

\section{Summary}

A persistent belief in popular literature from 1988 to 2008 that athletes could or would use pregnancy for a form of illegal blood doping was a barrier to healthy pregnancy and to the health of the sport. Analysis of the scientific and popular literature on doping, blood doping, pregnancy and athletics revealed that the proposition that a female athlete can gain competitive advantage from pregnancy or abortion is unsupported by current science. The two most consistent themes of purported oxygenation and hormonal advantage were carefully analyzed against current science and compared with existing definitions of doping and blood doping. Minor themes in the literature included the timing of pregnancy or pregnancy termination and ethical issues. Although pregnancy timing had no basis in science, ethical problems were consistently apparent in most of the literature.

\section{Recommendations}

It is important to share accurate scientific information about pregnancy-that pregnancy and abortion are not doping or blood doping - as soon as possible with student-athletes, coaches, athletic trainers, team physicians, athletic and university administrators, and university faculty. Hopefully this paper will prepare each stakeholder to respond to the myth of pregnancy doping with contemporary, accurate scientific knowledge. The healthiest, safest athletic culture will consist of stakeholders who are sensitive to the myths and negative characterizations about pregnant athletes, and sensitive to the psychological effects of unintended pregnancy. The best institutional responses will address the needs of both male and female athletes. For research scientists of every discipline in university and other organizational settings: this is a time for initiating stakeholder discussions on ethical behavior, abuse of power, and ethical institutional response to pregnancy. Critical analyses of the scientific and popular literature on a wide variety of topics that impact athletic participation are sorely needed to continue breaking down barriers to health. We 
must continue eating "this particular elephant one bite at a time" (WADA CEO referring to doping, quoted in O'Reilly \& Madill, 2007; p. 11).

For the USADA and NCAA, recommendations include a continued commitment to healthy athletic participation through banning unsafe substances and funding comprehensive efforts to continue objective biophysical testing. Revisions to the USADA Athlete Handbook (2006), NCAA Bylaw 31.2.3 (2008b) and the NCAA list of banned substances (2008c) to prohibit hCG for men only should be considered on the basis of Handelsman's arguments (2006). These revisions will increase USADA and NCAA congruence with World Anti-Doping Agency practices, reduce invasion of female athlete privacy, and may potentially reduce a pregnant athlete's fear of violating antidoping rules by testing positive for a banned substance (hCG); i.e., violating current USADA and NCAA antidoping rules. The fear of violating current antidoping rules could be a motivator to conceal pregnancy. The NCAA's powerful educational resources could support knowledge development in student-athletes, coaches, athletic trainers, team physicians, athletic and university administrators, and university faculty.

\section{References}

Abrahamson, A. (2006). What does a body good? Los Angeles Times. February 15, 2006, S-1. Retrieved February 25, 2009 from http://articles.latimes.com/2006/feb/15/sports/ sp-olyathletes 15 .

American Life League. (undated). Abortion statistics: Effective eye opener. American Life League Pro-Life Encyclopedia, Chapter 87. Retrieved March 12, 2009 from http:// www.ewtn.com/library/PROLENC/ENCYC087.htm.

Anonymous, M. (1998). Melissa's story: Pregnant female athlete. Yes, abortions happen to us too. Retrieved February 8, 2008, from www.fwhc.org/stories/melissa.htm.

Associated Press. (2007). Mercyhurst volleyball player charged with suffocating newborn. Associated Press. Retrieved June 10, 2009 from http://sports.espn.go.com/ncaa/news/ story?id=3026172.

Bessinger, R., McMurray, R., \& Hackney, A. (2002). Substrate utilization and hormonal responses to moderate intensity exercise during pregnancy and after delivery. American Journal of Obstetrics and Gynecology, 186, 757-764.

Bhasin, S., Woodhouse, L., Casaburi, R., Singh, A., Bhasin, D., Berman, N., et al. (2001). Testosterone dose-response relationships in healthy young men. American Journal of Physiology. Endocrinology and Metabolism, 28, E1172-E1181.

Carmina, E., Wong, L., Chang, L., Paulson, R., Sauer, M., Stanczyk, F., et al. (1997). Endocrine abnormalities in ovulatory women with polycystic ovaries on ultrasound. Human Reproduction (Oxford, England), 12(5), 905-909.

Catlin, D., Fitch, K., \& Ljungqvist, A. (2008). Medicine and science in the fight against doping in sport. Journal of Internal Medicine, 264, 99-114.

Clapp, J., III, \& Capeless, E. (1991). The $\mathrm{VO}_{2 \max }$ of recreational athletes before and after pregnancy. Medicine and Science in Sports and Exercise, 23(10), 1128-1133.

Davidson, M., London, M., \& Ladewig, P. (2008). Olds' Maternal-Newborn Nursing \& Women's Health Across the Lifespan (8th ed.). Upper Saddle River, NJ: Pearson Prentice Hall.

Epstein, D. (2008). Baby boost: For some female athletes, pregnancy may improve their performance. Sports Illustrated. August 18, 2008. Retrieved February 25, 2009 from http://vault.sportsillustrated.cnn.com/vault/article/magazine/MAG1143989/index.htm. 
Filicori, M., Cognigni, G., Gamberini, E., Parmegiani, L., Troilo \& Roset, B. (2005). Efficacy of low-dose human chorionic gonadotropin alone to complete controlled ovarian stimulation. Fertility and Sterility, 84(2), 394-401.

Ford, P. (2004). Athlete kept pregnancy secret, played for eight months. Cincinnati Enquirer. Retrieved February 8, 2008 from, http://www.wright.edu/news_events/community/ fall96/athletes.html.

Franke, W., \& Berendonk, B. (1997). Hormonal doping and androgenization of athletes: A secret program of the German Democratic Republic government. Clinical Chemistry, 34(7), 1262-1279.

Frye, A. (1997). Understanding Diagnostic Tests in the Childbearing Year (6th ed.). Portland, OR: Labrys Press.

Gaedeke, M. (1995). Laboratory and Diagnostic Handbook. Menlo Park, CA: AddisonWesley.

Gaedeke, M. (1997). Laboratory and Diagnostic Test Handbook. Menlo Park, CA: AddisonWesley.

Gordon, G. (2002). Maternal physiology in pregnancy. In S. Gabbe, J. Niebyl, \& J. Simpson (Eds.), Obstetrics: Normal and Problem Pregnancies (4th ed.). New York: Churchill Livingstone.

Hamilton, M. (2006). Elective performance enhancement surgery for athletes: Should it be resisted? Acta Universitatis Palackianae Olomucensis. Gymnica, 36(2). Retrieved March 12, 2009, from http://www.gymnica.upol.cz/index.php/gymnica/article/view/74/68

Handelsman, D. (2006). Clinical review: The rationale for banning human chorionic gonadotropin and estrogen blockers from sport. The Journal of Clinical Endocrinology and Metabolism, 91(5), 1646-1653.

Hogshead-Makar, N., \& Sorensen, E. (2008). NCAA Gender Equity Pregnant and Parenting Student-athletes: Resources and Model Policies. National Collegiate Athletic Association. Retrieved March 12, 2009 from http://www.ncaa.org/wps/ncaa?ContentID=39941.

Houlihan, B. (1999). Anti-doping policy in sport: The politics of international policy coordination. Public Administration, 77(2), 311-334.

Irish Times (2006). Karatantcheva gets two-year ban. Irish Times, January 12, 2006.

Kicman, A., Brooks, R., \& Cowan, D. (1991). Human chorionic gonadotropin and sport. British Journal of Sports Medicine, 25(2), 73-80.

Lehman College. (2001). Athletics hall of fame inducts six new members. Retrieved February 8, 2008, from http://www.lehman.edu/vpstud/apexathletics/fame/01inductees.html.

Life Issues Institute. (2002). Life Issues no. 2836: Olympic pregnancy. Life Issues Institute, May 20, 2002. Retrieved March 12, 2009 from http://www.lifeissues.org/radio/ r2002/05/r2836.html.

Lifesite (2002). Olympic athletes getting pregnant and aborting to boost performance. Lifesite, February 1, 2002. Retrieved March 12, 2009 from http://www.lifesitenews. com/ldn/2002/feb/02020102.html.

Lotgering, F., Van Doorn, M., Struijk, P., Pool, J., \& Wallenburg, H. (1991). Maximal aerobic exercise in pregnant women: heart rate, $\mathrm{O} 2$ consumption, $\mathrm{CO} 2$ production and ventilation. Journal of Applied Physiology, 70(3), 1016-1023.

Maxwell, E. (2002). Science and the Olympics. American Scientific Affiliation, Executive director's corner, May/June 2002, 44 (3). May/June 2002. Retrieved March 12, 2009 from http://www.asa3.org/asa/newsletter/MAYJUN02.htm.

McGovern, C. (2002). Brave new world: Going for gold: It takes blood, sweat and an abortion to be a winner. Report: Canada's Independent Newsmagazine. February 4, 2002.

McMurray, R., Hackney, A., Katz, V., Gall, M., \& Watson, W. (1991). Pregnancy-induced changes in the maximal physiological responses during swimming. Journal of Applied Physiology, 71(4), 1454-1459. 
Messer, L., Dole, N., Kaufman, J., \& Savitz, D. (2005). Pregnancy intendedness, maternal psychosocial factors and preterm birth. Maternal and Child Health Journal, 9(4), 403-412.

Mikkelson, B. (2002). Abortion doping. Retrieved March 12, 2009 from http://www.snopes. com/politics/sexuality/doping.asp.

Monroe, S. (2007). Office of Civil Rights: Dear colleague letter. Retrieved August 29, 2007 from http://www.ed.gov/about/offices/list/ocr/letters/colleague-20070625.html.

National Collegiate Athletic Association. (2008a). January 2008 NCAA Board of Directors/ Management Council Joint Report. Retrieved February 8, 2008, from http://www.ncaa. org/wps/portal/!ut/p/kcxml/04_Sj9SPykssy0xPLMnMz0vM0Y_QjzKLN4g38nYB SYGYxqb6kWhCjggRX4_83FSgeKQ5UMA0NEw_Kic1PTG5Uj9Y31s_QL8gNzSiPN9REQDSw7cx/delta/base64xml/L01JSk03dWIDU11BIS9JTGpBQUV5QUJFUkVSRUlrLzRGR2dkWW5LSjBGUm9YZnJDRUEhLzdfMF81VVYvMTQ0M DAw?WCM_PORTLET=PC_7_0_5UV_WCM\&WCM_GLOBAL_CONTEXT =/ $\mathrm{wps} / \mathrm{wcm} /$ connect/NCAA/Legislation+and+Governance/Committees/Division+I/ Board+Of+Directors/2008/January/BOD-MC+Final+Joint+Report+-+January+08.

National Collegiate Athletic Association. (2008b). Bylaw 31.2.3: NCAA banned-drug classes 2008-2009. National Collegiate Athletic Association. Retrieved March 11, 2009 from http://grfx.cstv.com/photos/schools/miss/genrel/auto_pdf/banned_drug_classes.pdf.

National Collegiate Athletic Association. (2008c). Drug testing program 2008-09. National Collegiate Athletic Association. Retrieved March 13, 2009 from http://www.ncaapublications.com/Uploads/PDF/DT\%20Program\%20Book\%202008-098066e117-09c34244-a00f-fa68a2c6c96c.pdf.

Operation Rescue West (2002a). Dead children of former Olympians to speak at Winter Games. Operation Rescue West, February 6, 2002.

Operation Rescue West (2002b). Getting pregnant to abort: An Olympic twist. Operation Rescue West, February 6, 2002.

O'Reilly, N., \& Madill, J. (2007). The World Anti-Doping Agency: The role of social marketing. Journal of Nonprofit \& Public Sector Marketing, 17(1-2), 1-26.

Pablinger, C., \& Gruber, G. (2005). World anti-doping regulations for 2005: Essential changes for athletes and physicians. Archives of Orthopaedic and Trauma Surgery, 126, 286-288.

Passignano, M., \& Crutcher, M. (2002). Getting pregnant to abort to improve athletic abilities. Lifetalk Television, January 2002. Retrieved March 13, 2009 from http://www. lifedynamics.com/Against_Abortion/Pro-life_Picture/?id=32.

Paulev, P-E. (1999). Textbook in Medical Physiology and Pathophysiology. Section IV: Respiratory System; Chapter 18 Exercise, Sports and Doping; p. 13 Pregnancy/Abortion as Doping. Retrieved March 12, 2009 from http://www.bioon.com/book/biology/ medicalphysiology/content.htm.

Plushnick-Masti, R. (2007). Mercyhurst volleyball player charged with suffocating baby. Associated Press in USAToday. Retrieved March 12, 2009 from http://www.usatoday. com/sports/2007-09-18-3535088694_x.htm.

Polit, D., \& Beck, C. (2007). Nursing Research: Generating and Assessing Evidence for Nursing Practice (8th ed.). Philadelphia: Lippincott, Williams \& Williams.

Portnoy, J. (2004) Lafayette student fights to break college norm. The Express Times, November 11, 2004.

Potts, K. (2001). Family matters: In many ways student-athletes learn parenthood by trial and error. 2001. Retrieved February 8, 2008, from http:/www.ncaa.org/wps/wcm/connect/ NCAA/NCAA+News/NCAA+News+Online/2001/Association-wide/Family+matters++5-7-01?pageDesign=Printer+Friendly+NCAA+News+And+Updates.

Public Television Station. (2008). Doping for the gold. PBS Program transcript, May 14, 2008. Retrieved March 12, 2009 from http://www.pbs.org/wnet/secrets/transcripts/ doping-for-gold-program-transcript. 
RealChoice. (2007). The right to do what she wants with her own body. RealChoice, November 15, 2007. Retrieved March 12, 2009 from http://realchoice.blogspot. com/2007_11_01_archive.html.

Religious Tolerance. (2002). Abortion news from 2002 - Jan to March: Allegations of "design abortions" at Olympics. ReligiousTolerance.org. Retrieved March 12, 2009 from http:// www.religioustolerance.org/abo_news_02.htm.

Rovegno, L. (2007). Athletes often forced into heartbreaking decisions. ESPN Outside the Lines. Retrieved February 8, 2008, from http://sports.espn.go.com/espn/ print?id=2865230\&type=story.

Sawka, M., Joyner, M., Miles, D., Robertson, R., Spriet, L., \& Young, A. (1996). American College of Sports Medicine position stand: The use of blood doping as an ergogenic aid. Medicine and Science in Sports and Exercise, 28(3), i-viii.

Schonbrun, Z. (2007). Fantasia Goodwin speaks about pregnancy. Syracuse Daily Orange. Retrieved February 8, 2008, from http://media.www.dailyorange.com/media/storage/ paper522/news/2007/04/25/Sports/ Year-In.Sports.Fantasia.Goodwin.Speaks.About. Pregnancy-2878171.shtml.

Sorensen, E., Sincoff, M., \& Siebeneck, E. (2009). The need for an effective student-athlete pregnancy \& parenting policy. Journal of Issues in Intercollegiate Athletics, 1, 25-45.

Stanek, J. (2007). Female athletes, the "weakened" state of pregnancy, and abortion doping. May 25, 2007. Retrieved March 12, 2009 from http://www.jillstanek.com/ archives/2007/05/female_athletes.html.

Stenman, U-H., Hotakainen, K., \& Alfthan, H. (2008). Gonadotropins in doping: Pharmacological basis and detection of illegal use. British Journal of Pharmacology, 154, $569-583$.

United States Anti-Doping Agency. (2006). Athlete handbook. United States Anti-Doping Agency. Retrieved March 18, 2009 from http://www.usada.org/files/active/athletes/ athlete_handbook.pdf.

Webb, R. (2004). Michael Moore's Fahrenheit 755: Baseball gets hammered, or the thrill of victory, the agony of da fetus. ESPN.com. July 28, 2004. Retrieved March 12, 2009 from http://sports.espn.go.com/espn/page2/story?page=webb/040728.

Willis, M. (2001). Helping paralympic athletes: Go for the glory. Retrieved February 8, 2008, from http://www.wright.edu/news_events/community/fall96/athletes.html.

Wolff, A., \& O'Brien, R. (1994). Pregnancy doping. Sports Illustrated, 81(23), 16.

World Anti-Doping Agency. (2009a). World anti-doping code. Montreal, Canada: World Anti-Doping Agency. http://www.nada-bonn.de/fileadmin/user_upload/nada/Downloads/Regelwerke/080305_WADA-Code_v2009_En.pdf.

World Anti-Doping Agency. (2009b). The World Anti-Doping Code 2009 Prohibited List: international Standard. Retrieved March 12, 2009 from http://www.uci.ch/Modules/ BUILTIN/getObject.asp?MenuId=MjIONQ\&ObjTypeCode=FILE\&type=FILE\&id= MzQxNzI\&.

Zander, E. (2007). Community struggles with circumstances of baby's death. WAHS11News, October 26, 2007. 